\title{
BMJ Open Development of a global health bachelor curriculum in China: a Delphi study
}

\author{
Li Guan, ${ }^{1,2}$ Pan Gao, ${ }^{1,2}$ SuYang Liu, ${ }^{1,2}$ YiSi Liu, ${ }^{1,2}$ XiangYu Li, ${ }^{1,2}$ FeiFei Liu, ${ }^{1,2}$ \\ ZongFu Mao, ${ }^{1,2}$ YuanAn Lu, ${ }^{3}$ Hao Xiang ${ }^{1,2}$
}

To cite: Guan L, Gao P, Liu SY, et al. Development of a global health bachelor curriculum in China: a Delphi study. BMJ Open 2019;9:e023893. doi:10.1136/ bmjopen-2018-023893

- Prepublication history for this paper is available online. To view these files, please visit the journal online (http://dx.doi. org/10.1136/bmjopen-2018023893).

$L G$ and $P G$ contributed equally.

Received 29 April 2018 Revised 13 November 2018 Accepted 15 November 2018

Check for updates

(C) Author(s) (or their employer(s)) 2019. Re-use permitted under CC BY-NC. No commercial re-use. See rights and permissions. Published by BMJ.

${ }^{1}$ Department of Global Health, School of Health Sciences, Wuhan University, Wuhan, China ${ }^{2}$ Global Health Institute, Wuhan University, Wuhan, China

${ }^{3}$ Department of Public Health Sciences, University of Hawaii at Manoa, Honolulu, Hawaii, USA

Correspondence to

Dr Hao Xiang;

xianghao@whu.edu.cn

\section{ABSTRACT}

Objective This study aimed to establish the first global health bachelor curriculum in China.

Design The Delphi methodology was used to determine expert consensus on which courses should be included in the global health bachelor curriculum. A literature review and a workshop proceeding were performed to generate courses. Then a two-round Delphi process was conducted with 28 invited experts from universities, health administrative departments and non-governmental organisations to rate courses using a 5-point Likert scale. Additionally, the experts could alter, add or delete courses as appropriate. Consensus was predefined as a mean score of 4 or above and the percent agreement (proportion of panel members scoring 'very important' or 'important') no less than $75 \%$.

Results The responses in the two-round Delphi process were $85.7 \%$ and $70.8 \%$, respectively. In the first round, 12 courses did not meet the inclusion criteria and were removed. Based on the participants' comments, 32 courses were included in round 2 . In the second round, the consensus was reached on 31 courses which were selected as the final curriculum. These courses were categorised into five modules, including General Knowledge, Methodology, Global Health Issues, Intercultural Communication, and Health Policy and Programme Management.

Conclusion This study established the first global health bachelor curriculum in China. It will provide guidance for other educational institutions to develop similar programmes or curricula in the future.

\section{INTRODUCTION}

With the rapid development of the global economy, more and more Chinese go abroad to study, work and travel, while more and more foreigners are visiting China for the same reasons. Health issues and health inequality have quickly become the challenges for China and other countries. ${ }^{1}$ Today, it is clear that infectious diseases have no borders and can spread readily from one country to another. ${ }^{2}{ }^{3}$ Many global health (GH) issues and major diseases can only be effectively controlled and resolved through international collaboration. ${ }^{2}$ A competent

\section{Strengths and limitations of this study}

This is the first study to develop a global health bachelor curriculum in China.

- This study take advantage of the Delphi methodology to gather expert opinions and consensus on the curriculum.

- A pilot survey was completed by faculty members at Wuhan University to explore the readability and feasibility of the questionnaire.

- A limitation of the study is that all of the international panel members were from the USA with no experts from other foreign countries.

GH workforce with sufficient training and expertise is needed to improve and maintain local and GH. ${ }^{45}$ Therefore, GH education in universities has become a new focus and has attracted widespread attention throughout the world. ${ }^{6}$

Over the past few years, GH education has increasingly been recognised and included in the curriculum in most western countries. From 2011 to 2014, nearly $95 \%$ of the publications related to $\mathrm{GH}$ education originated from North America and European countries. ${ }^{7}$ Conversely, only $2.9 \%$ emanated from Asia. ${ }^{7}$ The gap in the quantity of studies on GH education between high-income and middle-income countries is obvious. In addition, bachelor programmes in GH are mainly concentrated in high-income countries, including the USA, UK and Canada. ${ }^{6}$ For example, the Blizard Institute of Queen Mary University of London offers a Bachelor of Science (BS) degree in GH to help students develop an understanding of a range of public health issues at the global level. ${ }^{8}$ In the USA, the University of Southern California provides a BS programme in GH composing of courses in the basic sciences, international relations, health promotion and disease prevention. ${ }^{9}$ Such programmes, however, are rare in middle-income countries. There is 
an urgent need to establish and develop GH education programmes in these middle-income countries.

As China has moved from an aid-receiving country to an aid-providing country, there is an increasing demand for Chinese health professionals with knowledge and competency in GH. ${ }^{10}$ Over the past few years, Peking University, Fudan University and Wuhan University have established GH Departments and research centres to train GH professionals and promote China's involvement in $\mathrm{GH}$ activities worldwide. ${ }^{11}$ The $\mathrm{GH}$ programmes can provide Chinese health professionals to go abroad to help the developing world and also educate international students to help their own countries to address health issues and health inequalities. In addition, these programmes can help China establish a better healthcare system and provide evidence for future health policy-making to address health issues and health inequalities domestically. Nowadays, studies focusing on curriculum development for GH education in China are very limited.

This paper examines a Delphi process for developing the first GH bachelor curriculum in China. The curriculum was developed and reviewed by international GH experts. The results of this study may be helpful to educators and students in other institutions interested in developing GH education and training programmes in China and other countries.

\section{METHODS}

We employed the Delphi method to develop a GH bachelor curriculum. The Delphi method is an iterative process to gather and provide information by using a series of questionnaires to determine the degree to which experts agree about the issue discussed. ${ }^{12}$ There were three phases in this study.

\section{Phase I}

\section{Generation of the initial draft and questionnaire}

Three members of the writing team (LG, PG and SYL) undertook a web search to identify available curricula related to GH bachelor programmes in February 2013. Curricula from four universities (Arizona State, Georgetown, Kent State and Southern California) were selected. A literature review was then conducted via Google and PubMed using the search terms 'name of school'+'global health', 'global health program', 'bachelor of global health or international health'. Six articles that are highly relevant to GH education were retrieved. ${ }^{13-18}$

In March 2013, during a workshop on GH bachelor education, we held a brainstorming exercise to generate ideas on the potential courses to be included in the GH bachelor curriculum. To guide the workshop discussion, we adopted a widely cited GH definition: "GH is an area for study, research, and practice that places a priority on improving health and achieving equality in health for all people worldwide. GH emphasizes transnational health issues, determinates and solutions; involves many disciplines within and beyond the health sciences and promotes interdisciplinary collaboration; and is a synthesis of population-based prevention with individual-level clinical care ${ }^{\prime 19}$ Nine GH educators, 12 public health educators and 10 multidisciplinary experts from Peking University, Fudan University and Wuhan University were invited. The courses that were generated were discussed in depth and categorised into six modules, including General Knowledge, Interdisciplinary Knowledge, Methodology, Global Health Issues, Intercultural Communication, and Health Policy and Programme Management.

According to the collected information above, we generated an initial draft of $\mathrm{GH}$ bachelor curriculum composed of 52 courses in six modules. We designed a questionnaire for experts to review and determine which courses should be included in the curriculum. Each course was described with course name, learning objectives and a short description of the course content.

\section{Phase II}

Pilot survey

Before the formal investigation, five faculty members at Wuhan University were invited to complete a pilot survey to explore the readability and feasibility of the questionnaire. Based on their feedback, the first version of questionnaire was developed for the Delphi study.

\section{Recruitment of members in the Delphi study}

The inclusion criteria of Delphi panel members were defined before recruitment. The candidates were selected from universities, health administrative departments and non-governmental organisations. They should have GH experience in terms of teaching, research or working for the international health organisations. Limited by time and budget, we recruited 28 panel members according to the recommendations for Delphi studies. ${ }^{20}$

\section{Phase III}

Delphi round 1

In the first round, all 28 panel members were sent an email with the questionnaire and the informed consent form. They were invited to rate the 52 courses on a 5-point Likert scale ${ }^{21}$ from 1 (not important) to 5 (very important). In addition, they were asked to alter, add or delete courses as appropriate. The mean, SD and percent agreement (scoring 'very important' or 'important') were calculated for each course. Complete data were collected from 24 of 28 panel members, and the results were used to revise the questionnaire and establish a second version.

\section{Delphi round 2}

The survey process for round 2 followed that of round 1 . The 24 panel members who had participated in round 1 were invited to re-rate the selected courses. They were sent the second version of questionnaire, and 17 of them responded. Based on Diamond et $a l^{20}$ Delbecq $e t a l^{22}$ and Ludwig, ${ }^{23}$ this number is sufficient to conduct subsequent data analysis. 


\section{Data analysis}

All statistical analyses were performed using IBM SPSS Statistics V.19.0 to generate descriptive statistics. The importance for each course was determined by the mean score. The percent agreement of each course was the proportion of panel members rating the course as 'very important' and 'important'. There have been no universally accepted criteria for consensus in a Delphi study. ${ }^{12}$ Miller indicated that if a certain percentage of the votes fall into a predefined range, consensus can be achieved. ${ }^{24}$ In this study, we define that a mean score is of 4.0 or above and the percent agreement is no less than $75 \%$, the consensus is reached. ${ }^{2025}$

\section{Patients and public involvement}

This study has not involved any patient. We consider the participants in the Delphi study as part of the public involvement. There was no participant involved in developing the questionnaire or designing or conducting the study. We did not seek advice from the participants to interpret the results of the study. No plans have been conceived to disseminate the results to the study participants.

\section{RESULTS}

\section{Demographics of the Delphi panel members}

In round 1, $24(85.7 \%)$ of the 28 invited experts participated. In round 2, $17(70.8 \%)$ of the 24 responded. Delphi panel members had different academic background and expertise, and worked in the following areas: nutrition, physiology, epidemiology, environmental health and health policy. Five panel members from American universities (Duke, Florida, Hawaii and Tennessee) had been associated with Chinese universities and were familiar with Chinese GH education. Most participants were less than 50 years old, with more than 5 years of GH experience. There are no significant differences in the distributions of gender (Fisher's exact test $p=1.000$ ), age (Fisher's exact test $\mathrm{p}=0.433$ ), global health experience (Fisher's exact test $\mathrm{p}=1.000$ ) and organisation (Pearson $\chi^{2} \mathrm{p}=0.680$ ) between the participants of the first and second rounds. The detailed demographic characteristics of the Delphi panel are shown in table 1.

\section{Delphi round 1}

Of the 52 courses rated by panel members, 12 courses did not meet the inclusion criteria and were removed (table 2). One course (International Health Project Management) was added based on the recommendations of four panel members. Six courses were renamed (table 3). In addition, Social Anthropology and Medical Anthropology were combined to form a course called Culture Anthropology. Principles and Application of geographic information system (GIS), Global Burden of Disease, and Behaviour, Psychology and Health were incorporated into Research Methods in Global Health, Epidemiology and Mental Health, respectively. The

\begin{tabular}{|c|c|c|}
\hline Characteristics & Round 1 ( $n=24)$ & Round $2(n=17)$ \\
\hline \multicolumn{3}{|l|}{ Gender, n (\%) } \\
\hline Male & $18(75.0)$ & $12(70.6)$ \\
\hline Female & $6(25.0)$ & $5(29.4)$ \\
\hline \multicolumn{3}{|l|}{ Age (years), n (\%) } \\
\hline$<50$ & $18(75.0)$ & $15(88.2)$ \\
\hline$\geq 50$ & $6(25.0)$ & $2(11.8)$ \\
\hline \multicolumn{3}{|c|}{$\begin{array}{l}\text { Global health experience } \\
\text { (years), } \mathrm{n}(\%)\end{array}$} \\
\hline$<5$ & $6(25.0)$ & $5(29.4)$ \\
\hline$\geq 5$ & $18(75.0)$ & $12(70.6)$ \\
\hline \multicolumn{3}{|l|}{ Organisation, n (\%) } \\
\hline University & $14(58.3)$ & $11(64.7)$ \\
\hline Other institutions* & $10(41.7)$ & $6(35.3)$ \\
\hline
\end{tabular}

${ }^{*}$ Health administrative departments and non-governmental organisations.

course of Race, Culture and Health was incorporated into Health Social Determinants, which was then integrated into Introduction to Global Health. Comparative Health Systems, Introduction to Global Health Organisations and Global Health Promotion were incorporated into Global Health Governance. Following feedback, the Interdisciplinary Knowledge module was incorporated into the module of General Knowledge. Introduction to Global Health was moved from the module of Global Health Issues to the module of General Knowledge. As a result, the revised curriculum contained five modules and 32 courses.

\section{Delphi round 2}

In the second round, 32 courses were rated by 17 participants. The results of the second round are listed in table 4. Organisational Behaviour did not meet the inclusion criteria and was removed. Finally, consensus was reached on five modules and 31 courses.

\section{DISCUSSION}

This study established the first recommended GH bachelor curriculum in China. Through a two-round Delphi study, panel members reached consensus on 31 courses in five modules, which are to train students to gain essential knowledge and various skills to serve and practice in GH field. We believe that the curriculum will provide students with a strong background in understanding and addressing $\mathrm{GH}$ issues and prepare students to become health professionals with international competencies.

The module of General Knowledge comprises interdisciplinary courses covering psychological, social, economic and philosophical dimensions. It is well accepted that interdisciplinary knowledge is critical for GH undergraduates to recognise social, political and economic factors of disease and understand the current and emerging $\mathrm{GH}$ issues from different perspectives. ${ }^{19}{ }^{26-28}$ Most GH 
Table 2 Course scores in round 1

\begin{tabular}{|c|c|c|c|}
\hline Module & Course & Mean \pm SD & Agreement (\%) \\
\hline \multirow[t]{9}{*}{ General Knowledge } & Preventive Medicine & $4.63 \pm 1.01$ & 92 \\
\hline & Introduction to Ethics & $4.29 \pm 0.62$ & 92 \\
\hline & Probability and Statistics & $4.00 \pm 0.98$ & $71^{*}$ \\
\hline & Pathogenic Organisms & $3.87 \pm 1.06 \dagger$ & $67^{*}$ \\
\hline & Medical History & $3.54 \pm 1.06 \dagger$ & $58^{*}$ \\
\hline & Physiology & $3.43 \pm 1.12 \dagger$ & $46^{\star}$ \\
\hline & Human Anatomy & $3.22 \pm 1.13 \dagger$ & $42^{*}$ \\
\hline & Biochemistry & $3.09 \pm 0.90 \dagger$ & $25^{\star}$ \\
\hline & Advanced Mathematics & $3.04 \pm 1.04 \dagger$ & $21^{*}$ \\
\hline \multirow{7}{*}{ Interdisciplinary Knowledge } & Social Psychology & $4.17 \pm 0.82$ & 83 \\
\hline & Medical Anthropology & $4.13 \pm 0.74$ & 79 \\
\hline & Social Anthropology & $4.09 \pm 0.73$ & 75 \\
\hline & Race, Culture and Health & $4.09 \pm 0.73$ & 75 \\
\hline & Organisational Behaviour & $4.08 \pm 0.72$ & 79 \\
\hline & Behaviour, Psychology and Health & $4.00 \pm 0.67$ & 79 \\
\hline & Introduction to Eastern and Western Philosophy & $4.00 \pm 0.67$ & 79 \\
\hline \multirow[t]{2}{*}{ Methodology } & Epidemiology & $5.00 \pm 0.00$ & 100 \\
\hline & Biostatistics & $4.75 \pm 0.68$ & 96 \\
\hline \multirow{9}{*}{ Global Health Issues } & Introduction to Global Health & $4.67 \pm 0.56$ & 96 \\
\hline & Global Burden of Disease & $4.65 \pm 0.57$ & 92 \\
\hline & Non-Communicable Diseases & $4.63 \pm 0.58$ & 96 \\
\hline & Food and Nutrition Security & $4.63 \pm 0.58$ & 96 \\
\hline & Communicable Diseases & $4.58 \pm 0.65$ & 92 \\
\hline & Maternal and Child Health & $4.58 \pm 0.65$ & 92 \\
\hline & Case Studies in Global Health & $4.48 \pm 0.59$ & 92 \\
\hline & Global Health and Ageing & $4.43 \pm 0.73$ & 92 \\
\hline & Global Mental Health & $4.30 \pm 0.82$ & 83 \\
\hline \multirow[t]{8}{*}{ Intercultural Communication } & Health Professional English & $4.71 \pm 0.55$ & 96 \\
\hline & International Law & $4.30 \pm 0.82$ & 83 \\
\hline & Intercultural Communication & $4.26 \pm 0.86$ & 79 \\
\hline & Modern International Relationship & $4.13 \pm 0.74$ & 79 \\
\hline & International Political Economy & $4.13 \pm 0.74$ & 79 \\
\hline & Major World Religions & $3.54 \pm 0.78 \dagger$ & $46^{*}$ \\
\hline & The Second Language (French) & $3.42 \pm 0.83 \dagger$ & $58^{\star}$ \\
\hline & Global History & $3.33 \pm 0.96 \dagger$ & $38^{*}$ \\
\hline
\end{tabular}


Table 2 Continued

\begin{tabular}{llll}
\hline Module & Course & Mean \pm SD & Agreement (\%) \\
\hline Health Policy and Programme & Global Health Internship & $4.42 \pm 0.72$ & 88 \\
Management & Comparative Health Systems & $4.42 \pm 0.72$ & 88 \\
& Global Health Diplomacy Practice & $4.35 \pm 0.98$ & 79 \\
& Global Health Management & $4.26 \pm 0.86$ & 79 \\
& Introduction to Global Health Organisations & $4.26 \pm 0.75$ & 75 \\
& Global Health Promotion & $4.24 \pm 0.77$ & 79 \\
& Hygienic Managerialism & $4.09 \pm 0.90$ & $71^{\star}$
\end{tabular}

Likert scale: 1, not important; 2, somewhat important; 3, moderately important; 4, important; 5, very important.

*Percent agreement $<75 \%$.

†Mean score $<4.0$.

bachelor programmes in the USA encourage interdisciplinary coursework. ${ }^{29}$ Allegheny College, Arizona State University, Georgetown University and the University of California San Diego all offer interdisciplinary courses such as sociology, political sciences and economics which, however, are set in elective modules. ${ }^{30-33}$ In our GH bachelor programme, students are required to master interdisciplinary knowledge, which will ensure them to successfully work in GH field.

Through the web search of GH bachelor curricula abroad, we found that Kent State University provided a special course on the application of GIS in health research. ${ }^{34}$ As the most efficient way for global spatial and geographical mapping, ${ }^{35}$ GIS technology should be included in the Methodology module. However, considering that it may be difficult for students to understand the learning material, panel members suggested incorporating GIS technology into Research Methods in Global Health and students could choose this course as an elective one for further study. Also, we found that many colleges and universities in the USA provided research method courses in their GH bachelor curricula. For example, the University of Southern California offered 'core studies' as one of the required modules, which includes Health Behaviour Statistical Methods, Health Behaviour Research Methods and Directed Research. ${ }^{9}$ In the review of $\mathrm{GH}$ bachelor education in the UK, research methods and epidemiology were two of the most

Table 3 Recommended course name changes

\begin{tabular}{|c|c|}
\hline Original course name & $\begin{array}{l}\text { Course name after } \\
\text { renaming }\end{array}$ \\
\hline 1 Global Health Economics & Health Economics \\
\hline 2 Maternal and Child Health & $\begin{array}{l}\text { Introduction to Maternal } \\
\text { and Child Health }\end{array}$ \\
\hline 3 Global Mental Health & Mental Health \\
\hline 4 Environment and Health & $\begin{array}{l}\text { Environment and Global } \\
\text { Health }\end{array}$ \\
\hline 5 International Law & International Health Law \\
\hline 6 Global Health Management & Global Health Governance \\
\hline
\end{tabular}

frequently offered courses, and they were emphasised in the programmes at University of Oxford and King's College. ${ }^{6}$ As the Global Health Education Consortium has proposed the 'Methods, Tools, and Skills' module in $\mathrm{GH}$ undergraduate education, ${ }^{36}$ we believe that research methods are essential in the GH bachelor curriculum.

Intercultural competency training is a challenge for the success of GH education programmes. ${ }^{35}$ The most frequently mentioned core competency of GH for healthcare professionals is 'be able to communicate with different populations and work under various cultural environments and medical systems'. ${ }^{378}$ This competency was also a main focus of our GH bachelor programme and was emphasised repeatedly by potential employers of GH graduates of degrees. Sociocultural and political awareness is needed by GH professionals to work effectively across diverse geographical and cultural areas with a variety of populations and health policies. ${ }^{39} 40$ The ability of problem-solving in practical work should also be improved among $\mathrm{GH}$ professionals to deal with health problems in different regions and healthcare systems.

The module of Health Policy and Programme Management comprises both domestic and international internships. Prior studies have highlighted the benefits of GH internships which include (1) opening doors to applying the course theories in settings of limited resources domestically and internationally and engaging in collaborative research throughout the world ${ }^{41}$; (2) helping increase knowledge, develop skills and gain confidence and better cultural sensitivity ${ }^{42}$; ; and (3) providing opportunities for graduate programmes and jobs. ${ }^{29}$ Practicum or internship experiences have been consistently emphasised in GH bachelor programmes abroad. The five GH bachelor programmes in the USA (Allegheny College, Arizona State University, Duke University, New York University and University of California San Diego) require students to have practicum experiences and another three (Arizona State University, Mercer University and New York University) require students to have international experiences. ${ }^{29}$ These experiences are part of transformational learning components for students and should be promoted and encouraged. 


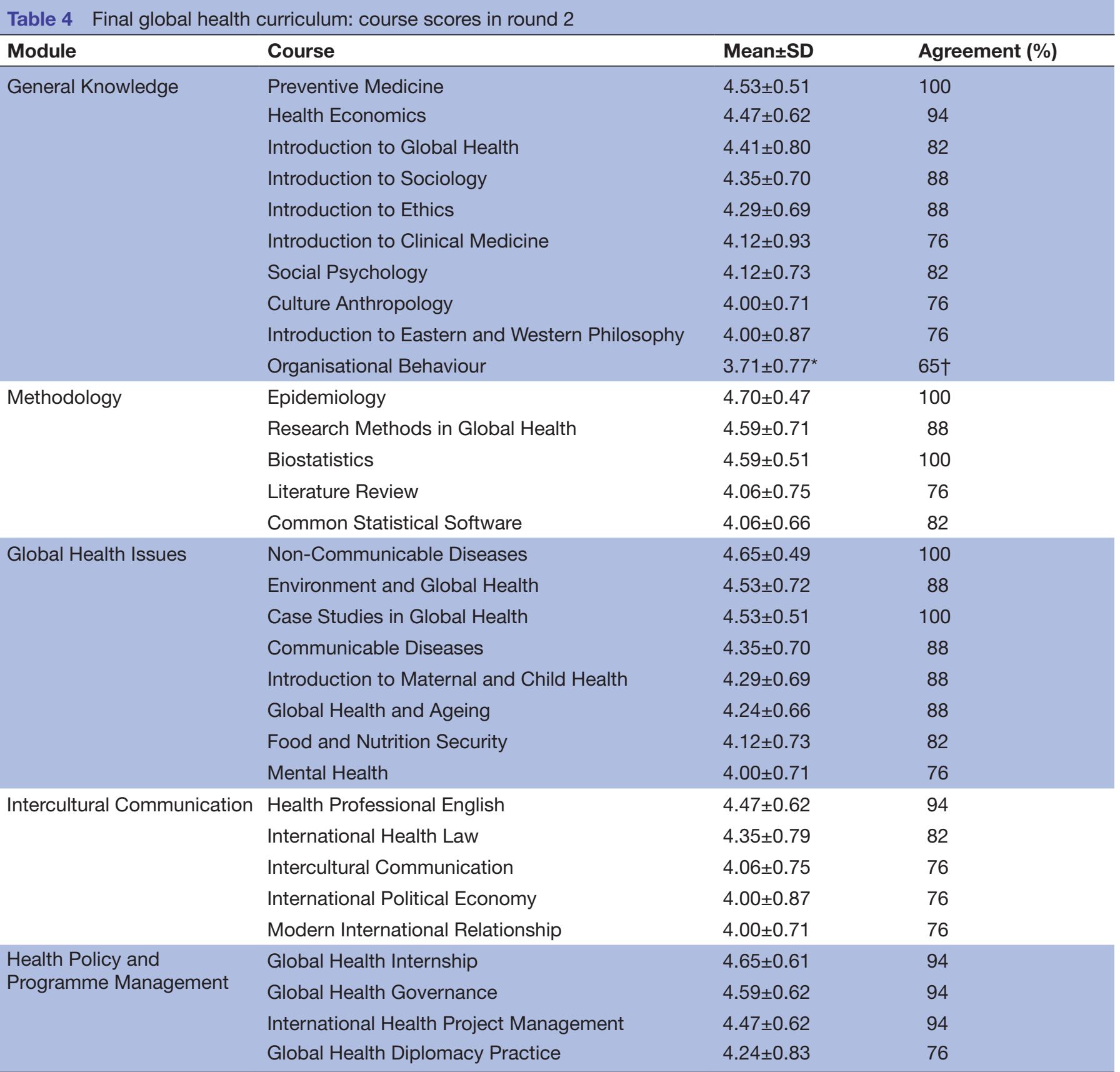

Likert scale: 1 , not important; 2 , somewhat important; 3, moderately important; 4, important; 5, very important.

${ }^{*}$ Mean score $<4.0$.

†Percent agreement $<75 \%$.

Our study was to identify the required GH major courses for a GH bachelor degree. All of the 31 courses listed in the curriculum are required $\mathrm{GH}$ major courses without elective courses, which are much more than the major courses required in the American universities for a GH bachelor degree. Despite this, the course contents of our curriculum have much in common with those found in the Western countries. They lay the foundation for Chinese GH students to study and work abroad in the future. This curriculum was implemented in September 2013 and the first group of students successfully completed the GH bachelor programme in 2017. Tested in both teaching and learning practices, the curriculum was proven to be practical. We would like to summarise the previous research work during the development of the curriculum to provide some information for future improvement of the curriculum. Currently, the faculty members of School of Health Sciences at Wuhan University are obtaining feedback from these graduates.

A limitation of this study is that all of the international panel members were from the USA. In the preparation phase, due to our limited professional network and financial support to recruit Delphi participants, we were not able to seek opinions from academics and GH 
practitioners from other foreign countries. As we and others know, it is important to seek advice from GH educators, researchers and practitioners working in low-income countries. They know much better than those in high-income countries about the knowledge and skills needed to function in the field and to offer solutions to solve GH issues in low-income countries, which are useful trainings for $\mathrm{GH}$ workforce. Five years later, with the development of $\mathrm{GH}$ education worldwide, we will continue to try to get feedback from those $\mathrm{GH}$ colleagues from low-income countries to share their experience on cultivation of GH undergraduates and discuss the proposed GH bachelor curriculum to identify areas of strength and weakness for further improvement.

\section{CONCLUSION}

In this study, the consensus was reached on five modules with 31 courses in the GH bachelor curriculum among international experts after two rounds of a Delphi study. This study broke new ground by developing the first GH bachelor curriculum in China. We hope that our study will provide some guidelines and references for other institutions to set up their GH programmes or curricula. This may help facilitate GH education in China as well as in other middle-income countries in the near future.

Acknowledgements We would like to thank Dr Guoxun Chen at the University of Tennessee and Dr Xinguang Chen at the University of Florida for their expertise and invaluable advice in revising the manuscript, and all of the stakeholders for providing detailed information and insightful comments.

Contributors All authors conceived and designed the study. LG and PG drafted this manuscript with the help of SYL, YSL, XYL, FFL, ZFM, YAL and HX. All authors contributed to writing, revising and editing the manuscript. All authors read and approved the final version of the manuscript.

Funding This work was supported by China Medical Board (grant no. 13-134).

Competing interests None declared.

Patient consent for publication Not required.

Ethics approval The ethical committee of School of Health Sciences at Wuhan University.

Provenance and peer review Not commissioned; externally peer reviewed.

Data sharing statement Data will be available from the corresponding author on request.

Open access This is an open access article distributed in accordance with the Creative Commons Attribution Non Commercial (CC BY-NC 4.0) license, which permits others to distribute, remix, adapt, build upon this work non-commercially, and license their derivative works on different terms, provided the original work is properly cited, appropriate credit is given, any changes made indicated, and the use is non-commercial. See: http://creativecommons.org/licenses/by-nc/4.0/.

\section{REFERENCES}

1. Xiang H, Mao ZF, Qin H, et al. Preliminary exploration of the training of global health professionals in China. Mod Prev Med 2015;42:382-4

2. Xiao HY, Wang PG, Mao ZF, et al. Theory and practice of global health professional personnel training in China. Northwest Med Educ 2015;3:406-8.

3. Ehn S, Agardh A, Holmer H, et al. Global health education in Swedish medical schools. Scand J Public Health 2015;43:687-93.
4. Frenk J, Chen L, Bhutta ZA, et al. Health professionals for a new century: transforming education to strengthen health systems in an interdependent world. Lancet 2010;376:1923-58.

5. Fineberg HV, Hunter DJ. A global view of health - an unfolding series. N Engl J Med 2013;368:78-9.

6. Harmer A, Lee K, Petty N. Global health education in the United Kingdom: a review of university undergraduate and postgraduate programmes and courses. Public Health 2015;129:797-809.

7. Liu Y, Zhang Y, Liu Z, et al. Gaps in studies of global health education: an empirical literature review. Glob Health Action 2015;8:25709.

8. Queen Mary University of London. BSc in global health. 2018 http:// www.qmul. ac.uk/undergraduate/coursefinder/courses/114962.html (accessed 12 Mar 2018).

9. University of Southern California. USC health promotion disease prevention and global health programs. $2018 \mathrm{https} / / / \mathrm{hpdp} . u s c . e d u /$ education.php?sub=BSGH (accessed 12 Mar 2018).

10. Chi C, Tuepker A, Schoon R, et al. Critical evaluation of international health programs: reframing global health and evaluation. Int $J$ Health Plann Manage 2018;33:511-23.

11. Zhang CX, Mao ZF. Fundamentals of the discipline of global health. Chin J Dis Control Prev 2014;18:1003-7.

12. Hsu CC, Sandford BA. The Delphi technique: making sense of consensus. Practical Assess Res Eval 2007;12:1-8.

13. Brewer TF, Saba N, Clair V. From boutique to basic: a call for standardised medical education in global health. Med Educ 2009;43:930-3.

14. Walling A, Merando A. The fourth year of medical education: a literature review. Acad Med 2010;85:1698-704.

15. Johnson O, Bailey SL, Willott C, et al. Global health learning outcomes for medical students in the UK. Lancet 2012;379:2033-5.

16. Stys D, Hopman W, Carpenter J. What is the value of global health electives during medical school? Med Teach 2013;35:209-18.

17. Khan OA, Guerrant R, Sanders J, et al. Global health education in U.S. medical schools. BMC Med Educ 2013;13:1-7.

18. Peluso MJ, Forrestel AK, Hafler JP, et al. Structured global health programs in U.S. medical schools: a web-based review of certificates, tracks, and concentrations. Acad Me 2013;88:124-30.

19. Koplan JP, Bond TC, Merson MH, et al. Towards a common definition of global health. Lancet 2009;373:1993-5.

20. Diamond IR, Grant RC, Feldman BM, et al. Defining consensus: a systematic review recommends methodologic criteria for reporting of Delphi studies. J Clin Epidemiol 2014;67:401-9.

21. Likert R. A technique for the measurement of attitudes. Arch Psych 1932;22:1-55.

22. Delbecq AL, Van de Ven AH, Gustafson DH. Group techniques for program planning. Glenview, IL: Scott, Foresman, and Co, 1975.

23. Ludwig B. Predicting the future: have you considered using the delphi methodology? JOE 1997;35:1-4

24. Miller LE. Determining what could/should be: the Delphi technique and its application. Paper presented at: the annual meeting of the Mid-Western Educational Research Association. Columbus, Ohio, 2006.

25. Downing J, Knapp C, Muckaden MA, et al. Priorities for global research into children's palliative care: results of an International Delphi Study. BMC Palliat Care 2015;14:1-10.

26. Rowson M, Willott $\mathrm{C}$, Hughes $\mathrm{R}$, et al. Conceptualising global health: theoretical issues and their relevance for teaching. Global Health 2012;8:36.

27. Palmer VS, Mazumder R, Spencer PS. Interprofessional global health education in a cosmopolitan community of North America: the iCHEE experience. Acad Med 2014;89:1149-52.

28. Pfeifle A, Earnest M. The creation of an institutional commons: institutional and individual benefits and risks in global health interprofessional education. J Law Med Ethics 2014;42:45-9.

29. Drain PK, Mock C, Toole D, et al. The emergence of undergraduate majors in global health: systematic review of programs and recommendations for future directions. Am J Trop Med Hyg 2017;96:16-23

30. Allegheny College. Global health major. 2018 http://sites. allegheny. edu/global health/global-health-major/ (accessed 12 Mar 2018).

31. Arizona State University. Global health undergraduate degrees. 2018 https:// webapp4.asu.edu/programs/t5/roadmaps/\% 20ASU00/\%20LASSHBA/null/ALL/\%202017 (accessed 12 Mar 2018).

32. Georgetown University. Biology of global health major. 2018 https:// biology. georgetown.edu/undergraduate/globalhealth (accessed 12 Mar 2018).

33. University of California San Diego. Bachelor of arts in global health. 2018 http://globalhealthprogram.ucsd.edu/undergraduate-program/ major.html (accessed 12 Mar 2018). 
34. Kent State University. BSPH in global health. 2018 https://www.kent. edu/public health/bachelor-science-public-health-bsph-global-health (accessed 12 Mar 2018).

35. Chen X. Understanding the development and perception of global health for more effective student education. Yale $\mathrm{J} \mathrm{Biol} \mathrm{Med}$ 2014;87:231-40.

36. Xiang H, Mao ZF, Qin H. Review of undergraduate programs on global health in American universities. Mod Prev Med 2015;42:190-2.

37. Battel-Kirk B, Barry MM, Taub A, et al. A review of the international literature on health promotion competencies: identifying frameworks and core competencies. Glob Health Promot 2009;16:12-20.

38. Peluso MJ, Encandela J, Hafler JP, et al. Guiding principles for the development of global health education curricula in undergraduate medical education. Med Teach 2012;34:653-8.

39. Jogerst $\mathrm{K}$, Callender B, Adams V, et al. Identifying interprofessional global health competencies for 21st-century health professionals. Ann Glob Health 2015;81:239-47.
40. Wilson L, Callender B, Hall TL, et al. Identifying global health competencies to prepare 21st century global health professionals: report from the global health competency subcommittee of the consortium of universities for global health. J Law Med Ethics 2014;42:26-31.

41. Francis ER, Goodsmith N, Michelow M, et al. The global health curriculum of Weill Cornell Medical College: how one school developed a global health program. Acad Med 2012;87:1296.

42. Jeffrey J, Dumont RA, Kim GY, et al. Effects of international health electives on medical student learning and career choice: results of a systematic literature review. Fam Med 2011;43:21-8.

43. Gladding S, Zink T, Howard C, et al. International electives at the university of Minnesota global pediatric residency program: opportunities for education in all Accreditation Council for Graduate Medical Education Competencies. Acad Pediatr 2012;12:245-50. 